\title{
Infecciones micóticas: un problema de salud de importante diagnóstico
}

\author{
Fungal infections: a health problem of important diagnostic
}

Hasta hace algunos años las infecciones micóticas se consideraban de baja prevalencia y de poca relevancia en la salud humana, por lo que el desarrollo de pruebas diagnósticas y nuevos agentes antimicóticos no representaba una prioridad. No obstante, la epidemiología de las infecciones fúngicas ha cambiado de manera importante en las últimas décadas, debido principalmente a los cambios en el estado inmunológico del hospedero humano, que los ha hecho más susceptibles a este tipo de infecciones, y a las condiciones medioambientales, que han llevado no solo a una mayor distribución de las especies reconocidas anteriormente como patógenas, sino a la aparición de nuevas especies potencialmente patógenas, algunas de las cuales son menos sensibles o resistentes a los tratamientos actualmente disponibles. Esta situación ha llevado a un incremento importante en el número de personas con infecciones por hongos, principalmente en aquellas en condiciones de inmunosupresión transitoria o permanente, como los sometidos a tratamientos prolongados con corticosteroides ( $p$. ej. pacientes trasplantados de órganos o con enfermedades autoinmunes) y las infectadas con el virus de la inmunodeficiencia humana $(\mathrm{VIH})$.

Solo hasta finales del siglo $X X$ los hongos fueron reconocidos como patógenos humanos importantes y fue a partir de ese momento que se despertó el interés y la necesidad de llevar a cabo investigaciones básicas y aplicadas para el estudio de estas infecciones y para el desarrollo de nuevos agentes antimicóticos. A pesar de estos esfuerzos y avances, la epidemiología real de las infecciones por hongos aún es desconocida, debido probablemente a la carencia de un sistema de reporte obligatorio controlado y de guías epidemiológicas locales e internacionales; además, en parte, a la falta de sospecha clínica por parte del personal médico y, en consecuencia, de un diagnóstico por el laboratorio oportuno. A su vez, las dificultades para establecer los diagnósticos micológicos confirmatorios han dado lugar a la administración "empírica» de antifúngicos, el uso descontrolado de ellos y la falta de instauración de un tratamiento adecuado de acuerdo a la enfermedad establecida y el agente causal implicado. Como resultado de esto, es evidente el desarrollo de resistencia por parte de diferentes especies a los antimicóticos de uso común, lo que complica aún más el panorama actual y el futuro del manejo y control de las infecciones fúngicas.

El diagnóstico clínico de la infecciones fúngicas no es fácil, debido principalmente a que los síntomas y los signos son variados, dependiendo del agente etiológico, la localización de la infección y el estado inmune del individuo afectado. De esta manera, el diagnóstico micológico definitivo debe estar orientado a la correlación de un conjunto de elementos epidemiológicos, clínicos y de laboratorio. Actualmente, la observación de estructuras micóticas por microscopía y el cultivo de 
muestras biológicas continúan siendo el estándar de referencia para el diagnóstico micológico por laboratorio; sin embargo, estos métodos convencionales no cuentan con la sensibilidad y la especificidad suficiente para establecer un diagnóstico certero. En consecuencia, se han desarrollado métodos basados en la detección de anticuerpos y antígenos, y, más recientemente, técnicas moleculares dirigidas a la detección de secuencias de ADN específicas de género y especie, y a la obtención de perfiles proteicos determinados, los cuales parecen ser alternativas promisorias para el diagnóstico micológico de manera más rápida y confiable.

La Clínica y el Laboratorio que presentamos en este número de Medicina \& Laboratorio brinda una idea general sobre las técnicas de laboratorio utilizadas en el diagnóstico de las infecciones fúngicas, desde lo convencional hasta lo molecular, dando un paso por las micosis más relevantes, los principales agentes causales y su importancia epidemiológica, con el fin de ofrecer a la comunidad médica y al personal del laboratorio información que pueda contribuir a conocer las ventajas y limitaciones de cada una de estas técnicas y, a su vez, a orientar de la mejor manera a la obtención de un diagnóstico micológico correcto y oportuno. Además, motivar a la comunidad científica al desarrollo de nuevas investigaciones, pues aún queda mucho por revisar, aprender y realizar en este campo.

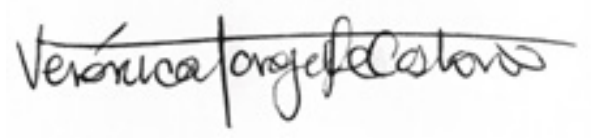

\section{Verónica J. Tangarife Castaño.}

MB, Candidata a MSc. en Ciencias Básicas Biomédicas.

Coordinadora Científica, Editora Médica Colombiana S.A. (EDIMECO S.A.)

Medellín, Colombia, junio 2015 